\title{
LAS ESTAMPAS DE ALCONEDO
}

\section{P O R}

\section{FRA NCISCO DE I A M A Z A}

$\mathrm{F}^{\mathrm{N}}$ el archivo de manuscritos de la Biblioteca de Estudios Latinoamericanos de la Universidad de Texas, que perteneció a la colección de don Genaro García, existe un expediente inquisitorial relacionado con el insigne platero y pintor José Luis Rodríguez Alconedo. Lo publicamos en estos Anales agradeciendo la cortesía de la Biblioteca en mostrarnos el documento y a la señorita bibliotecaria Nattie Lee Benson por sus finas atenciones $y$ encargarse de ordenar fotografiar las estampas que reproducimos.

Dos veces me he ocupado en estos Anales del artista: en 1940 con un ensayo lo más completo que pude escribir entonces sobre la vida y la obra de Alconedo (No. 6, págs. 39 a 56) y en 1944 analizando otro expediente de la Inquisición, relativo al pintor José Máynez, a quien acusó Alconedo por sospechoso de herejia (No. 11, págs. 93-94).

Años después, en 1808, se autodenunció Alconedo ante la Inquisición para curarse en salud de ciertos chismes que andaban en su contra (Anales, No. 6, pág. 45) y en este documento hace alusión al pequeño enredo que ahora publicamos. Decía entonces que "por los años de 1793" fué comisionado fray Francisco de Bolea para recogerle "una estampa y una miniatura", entregando él, además, "de voluntad, otras estampas desnudas y las figuras de la Academia en varias actitudes..." Añadió entonces que esas estampas no contenían "pasajes torpes y provocativos, por ser destinadas sólo para estudio que para el efecto las tenía por ser profesor ..." 
Sin embargo, a juicio de los inquisidores, según vemos en el presente documento, si resultaron algunas estampas "obscenas" y decomisaron catorce de las diez y seis que entregó. Respecto de la colección encuadernada en pasta de filete con las ciento viente y tres estampas de la "Fábula de la Gentilidad" parece que fueron idulgentes los inquisidores y se la devolvieron integra.

La primera carta del expediente de Austin es la del propio Alconedo pidiendo la devolución de su obra de arte. Es autógrafa, de buena y firme letra, con las deliciosas faltas de ortografía - hasta en eso fué goyesco Alconedo- del "hase" o del "precente".

El secretario de la Inquisición remitió los grabados al Calificador fray Ram0n Casaus, dominico de Porta Coeli, el cual entregó el Libro al platero, pero habiéndole quitado diez estampas "por muy torpes, tanto por su desnudez como por los infames hechos de las fábulas que se presentan en los temas más lascivos". Dejó cuatro para que Alconedo las tuviese "en la debida reserva".

Hubo un error en cuanto al número de estampas, pues al fin se determinó en que las catorce peligrosas permaneciesen en el Tribunal, como en efecto quedaron, cosidas al expediente que hoy guarda la Universidad de Texas.

Hay que recordar, al propósito, que, un poco antes, en 1791, el pudibundo arquitecto don Antonio González Velázquez había denunciado a Manuel Tolsá de que éste tenía en su poder "una pintura francesa que es una estampa iluminada, puesta con su cristal y marco... de dos vistas... que le ha parecido al declarante no sólo indecente, sino positivamente obscena..." Como le preguntasen qué representaba la estampa González Velázquez declaró que era "una mujer sentada en una silla y delante de ella un joven arrodillado en acción de besarle la mano, más por el otro lado está la moza sentada en una cama, descubiertos los pechos y las piernas, un brazo extendido en ademán de retirar al hombre, cuyas manos están en ademán de alzar la ropa e introducirse en lo más secreto; todo con la mayor viveza, dibujo, talla y colorido, a que se junta el adorno de marco y cristales; naturalmente se llevan los ojos del menos curioso, y dicha pintura la tiene de manifiesto, colgada en su recámara". El expediente sólo termina en que se le recogió el cuadro y cuatro estampas y se pensó darle "una severa reprensión". ${ }^{1}$

1 Boletín del Archivo General de la Nación, t. vr, enero-febrero de 1935, págs. 53 a 56 . 
Desde la Revolución Francesa andaba El Santo Oficio a caza de herejías dimanadas de ella, encontrando siempre lo que, hipócritamente, no iacía España: volver los ojos al bello mundo libre de lo clásico.

A continuación transcribimos las cartas del expediente y los pies de las estampas. Estas formaron parte de un libro y están firmadas por los pintores y grabadores que las hicieron, los más ilustres de la Francia de fines del siglo xvirr. Reproducimos también algunas de las estampas, las más hermosas de la colección $y$, tal vez, las que parecieron más "torpes" a los señores inquisidores.

Ilmo. Sr.

Dn. José Luis Rodríguez Alconedo, Patrón de Platería, con el devido respeto: hase precente a V.S. Ilma. que por el año de 94 o por el de 95 se me recogieron de orden de este Sto. Oficio 16 estampas sueltas de diversos asuntos y una coleccion encuadernada en pasta de filete encarnado con más de 123 estampas de la fábula de la Gentilidad y como propias de el estudio para adelantamiento de mi facultad.

A V.S. Ilma. suplico se sirva mandarlas examinar para que las que me fueren rocivas se separen y se me devuelvan las útiles.

Ilmo. Sr.

José Luis Rodríguez Alconedo--Rúbrica.

M. R. P. Regente Calificador Dr. Fr. Ramón Casaus.

Con esta acompaño a V. M. de orden del Tribunal el adjunto Libro de Estampas para que las reconozca y también para que juzgando $\mathrm{V}$. M. que puede correr dicho libro lo entregue a su Dueño el Platero poblano Dn. Jph. Rodríguez previniéndole que en lo subcesivo lo tenga con la devida reserva para no dar lugar a otra denuncia, pero que si V. M. encuentra alguna estampa que sea digna de proscripción la arranque y embie a este tribunal devolviendo esta.

Dios ge. m". a". a V. M. Inqon. de México a 3 de Abril de 1799.

Dr. Bernardo Ruiz de Molina Srio.--Rúbrica.

Ilmo. Sr.

En obediencia del superior derecho de V.S.I. entregué el Libro de Estampas al Platero, D. Josef Rodz. el día 1o. de este, habiendo arrancado estas diez por muy 
torpes, tanto por su desnudez como por los infames hechos de las fábulas que se presentan en los temas más lascivos. Como quedaban unas cuatro estampas algo indecentes le previene que se le permitan por razón de su oficio para la utilidad del Dibuxo pero que se le encargaba la conciencia para que las tuviese con la debida reserva y me respondió que para obedecer mejor las arrancaría del libro y las guardaría separadamente sin que nadie las viese.

Colegio de Porta Coeli y Abril 16 de 1799.

Ilmo. Sr.

Dr. Fr. Ramón Casaus, Calificador.-Rúbrica.

R. P. Dr. Fr. Ramón Casaus.

Calificador de este Sto. Oficio.

En el oficio del 20 del corriente que de orden del Trib. libré a V. M. le acompañé las mismas estampas que aora también remito porque a tiempo que se presentó el platero Dn. Luis Rodz. pidiendo se le entregase el Libro de Estampas que se le recogió, pidió otras diez y seis que por separado se le recogierorr; en esta inteligencia prevengo a V. M. en virtud de lo acordado que haga comparecer al dicho platero y le manifieste las referidas estampas para que las reconozca $y$ aparte las que fuesen sucias, las que le entregará $V$. M. con tal que no sean de las obscenas, devolviendo estas al Tribunal con alguna otra que no fuere de las que pidió, sin recurrir ya al libro de Estampas que ya tiene expurgado $V$. M. a quien Dios $\mathrm{g}^{\mathrm{e}}$. $\mathrm{m}^{\circ}$. $\mathrm{a}^{*}$. Inq ${ }^{\circ \mathrm{an}}$, de México, 25 de Abril 1799.

Dn. Bernardo Ruiz de Molina.-Rúbrica.

Ilmo. Sr.

Ninguna de las estampas que V.S: I. me ha remitido pertenece a D. Luis Rodz. Este dice que las que pide son de papel de marca de a pliego y de a medio pliego. Por ser de estudios Académicos, muy utiles para diseños, ruega a la bondad notoria de V.S.I., tenga a bien hacer que se busquen y reconozcan. Hace cinco años que V.S.I. las recogió y hasta ahora no se habia atrevido a hacer presente esta solicitud y protesta que no quisiera ocasionar la más leve molestia al Sto. Tribunal ni hacerse importuno llamando su atención a cosas tan leves sino tubiese plena confianza en la bondad y paciencia de V.S.I.

Colegio de Porta Coeli y Abril 26 de 1799.

Ilmo. Sr.

Dr. Fr. Ramón Casaus, Calif.-Rúbrica. 
DOI: http://dx.doi.org/10.22201/iie.18703062e.1955.23.578

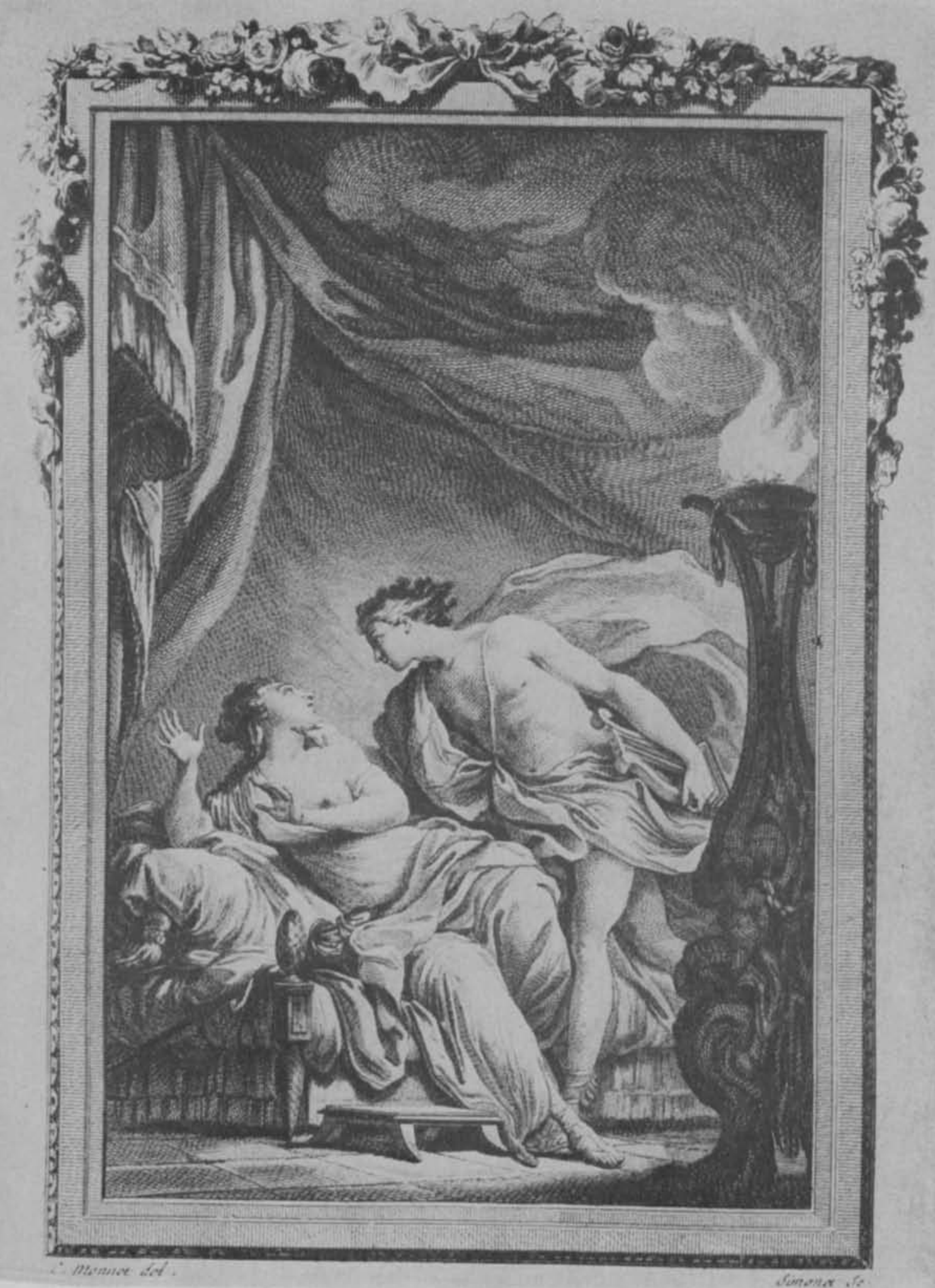




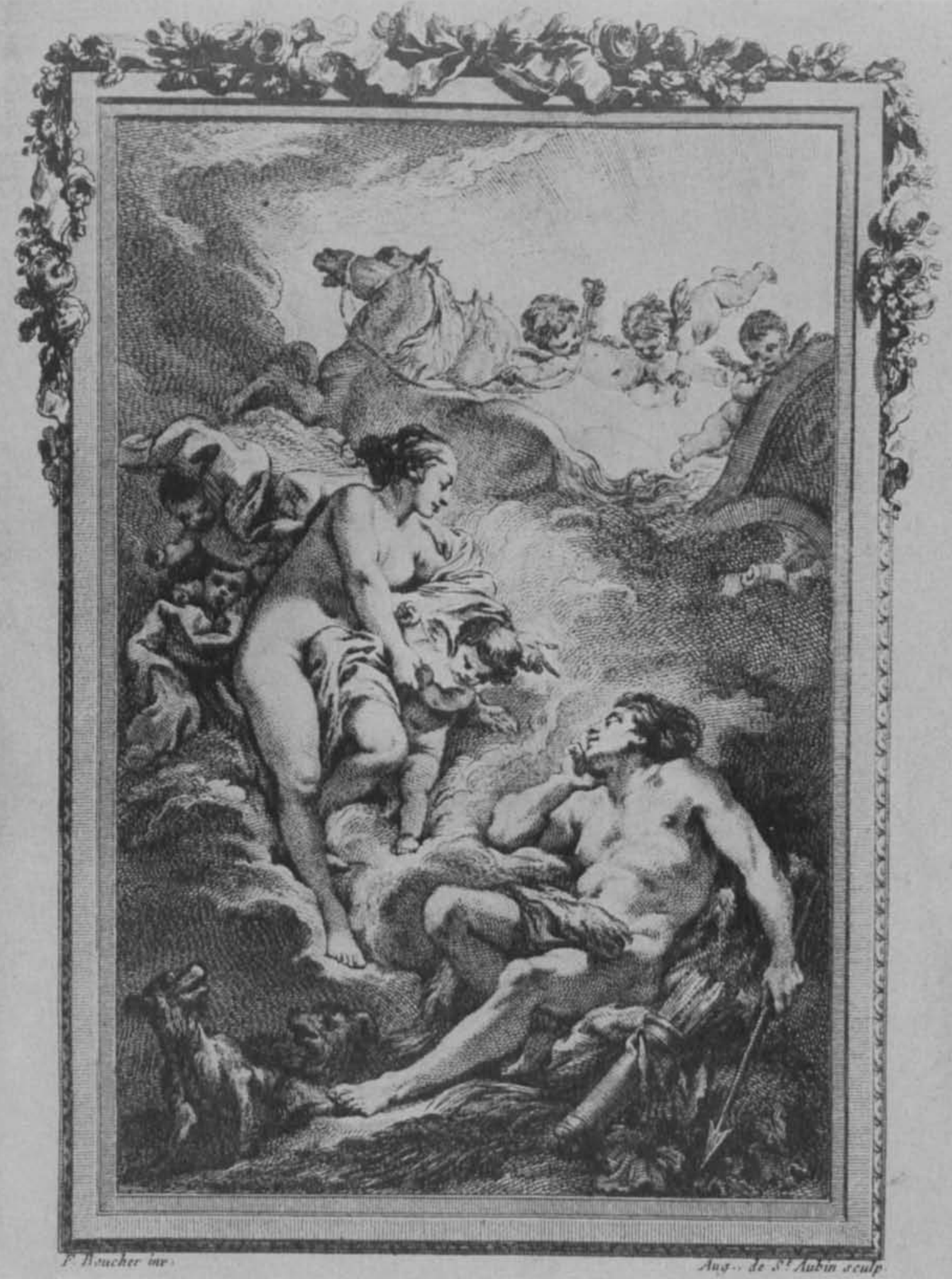




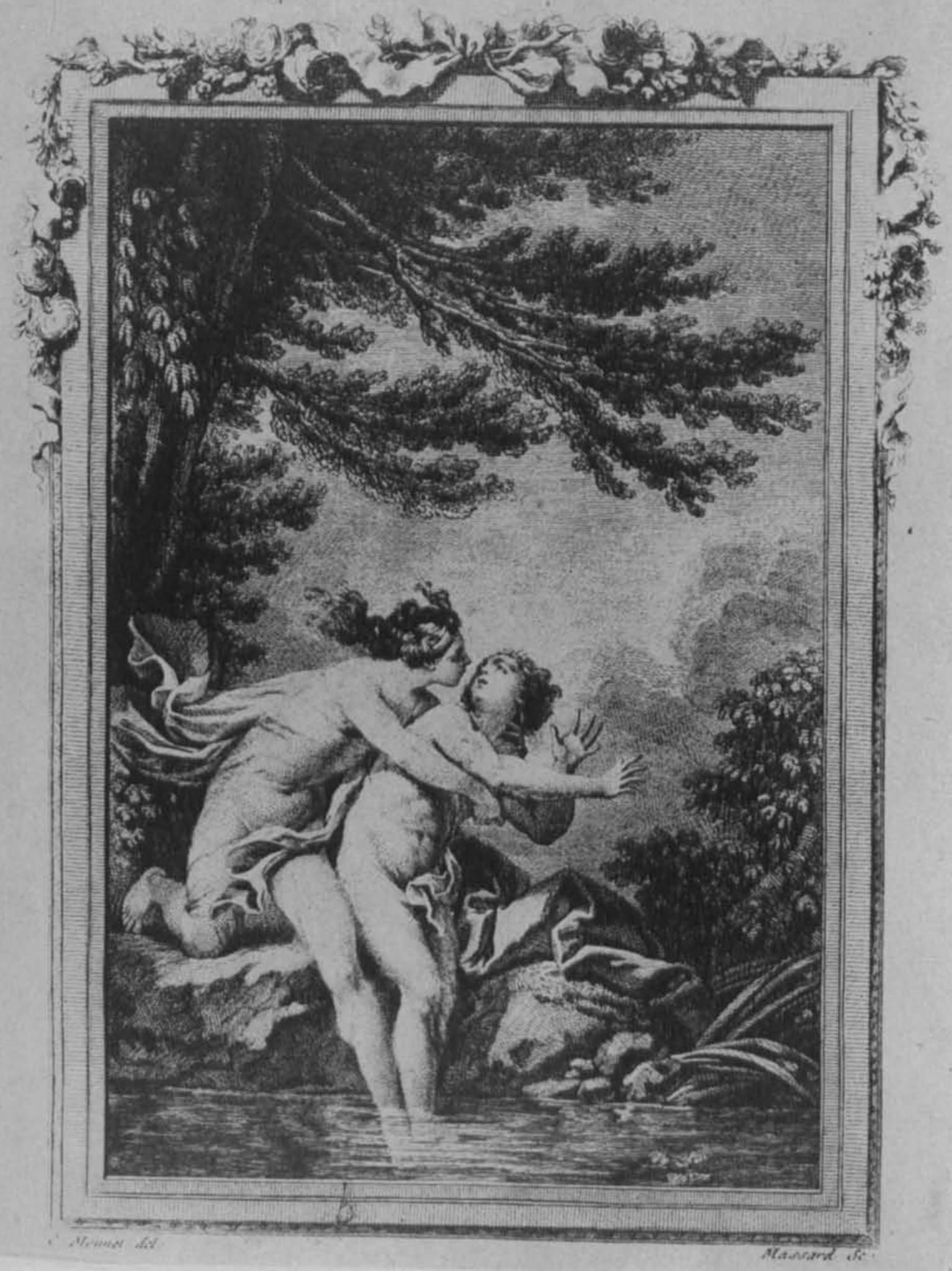




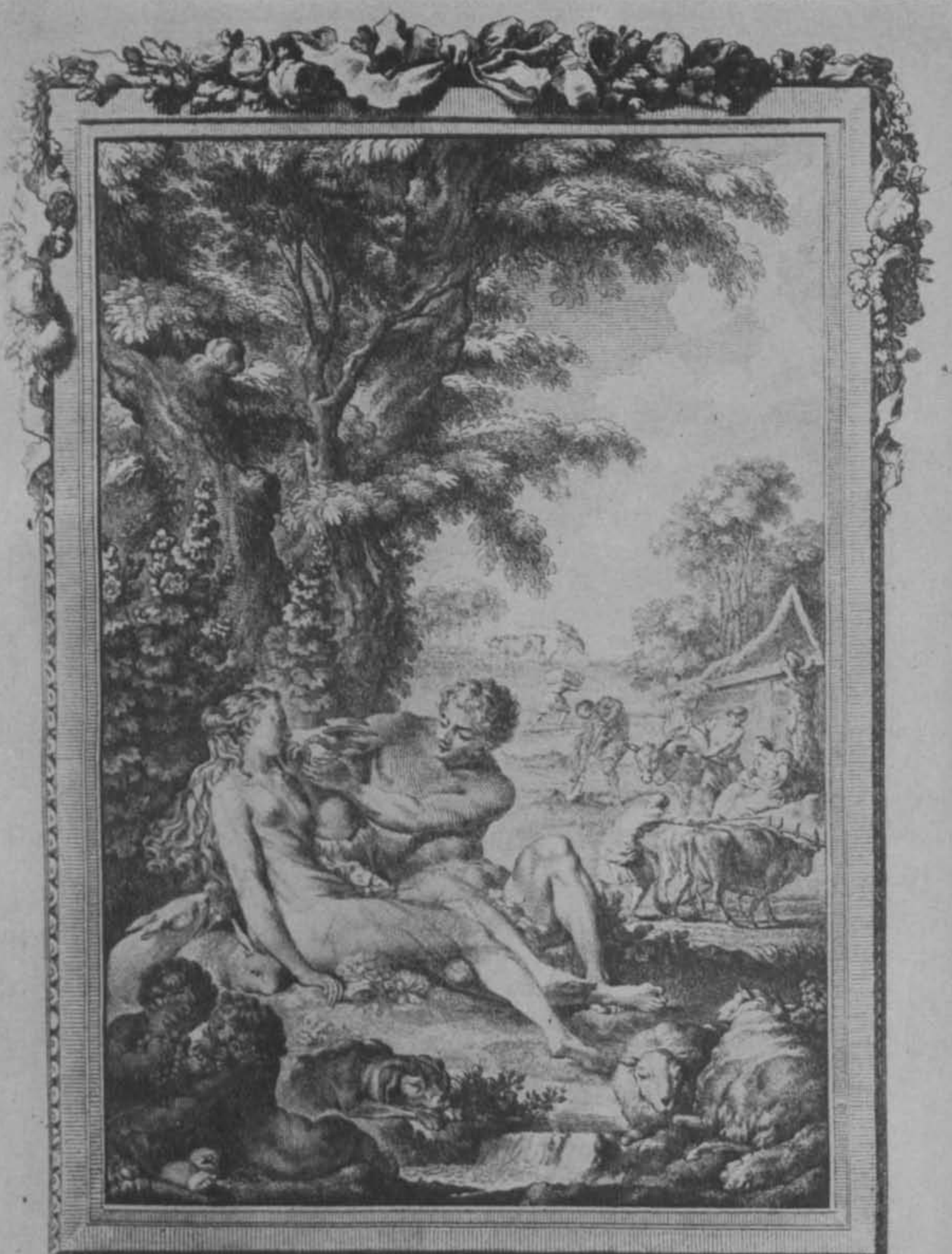

C. Xwow huved det.

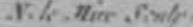




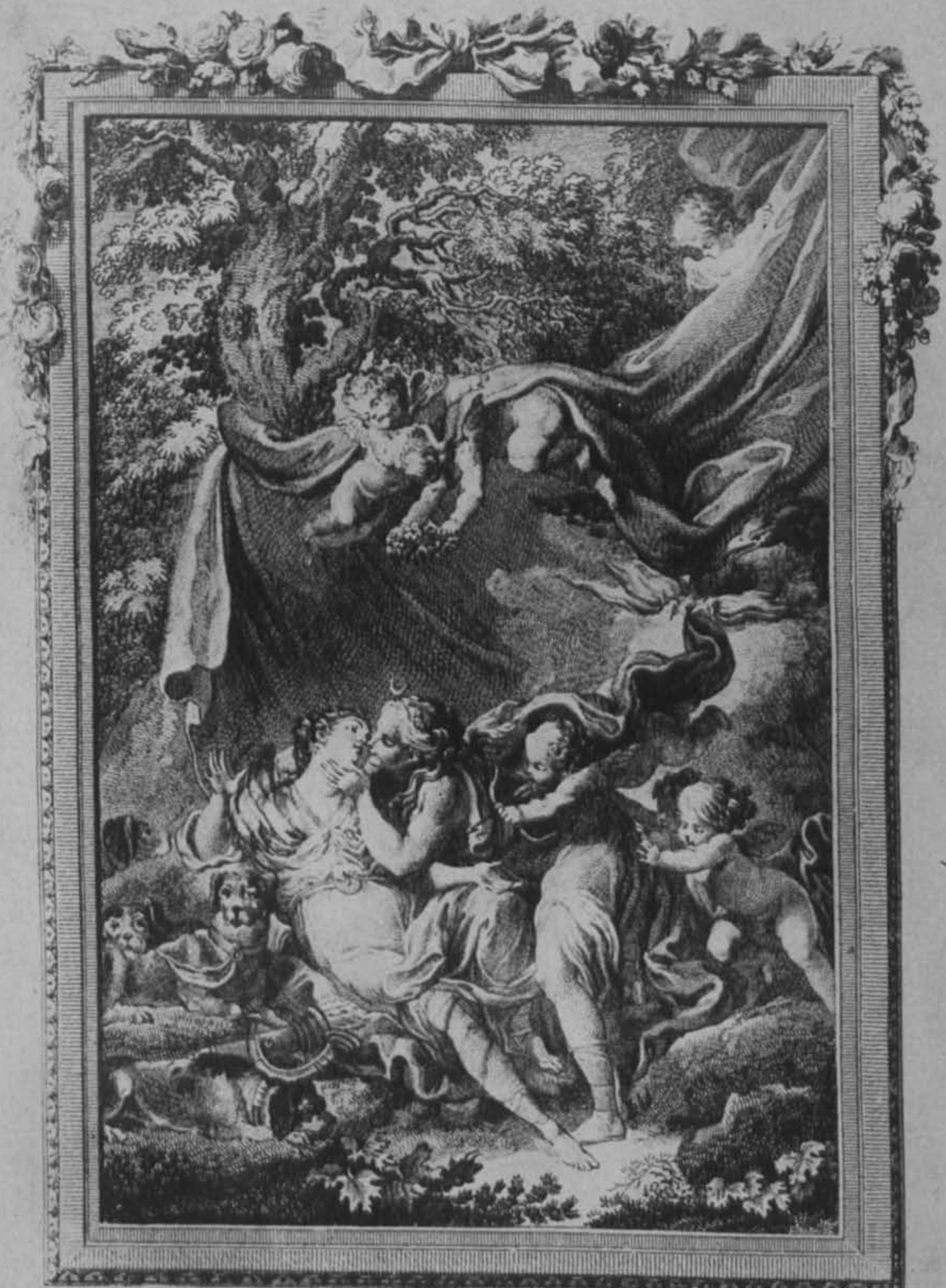




\section{R. P. Regente y Calific.}

Dr. Fr. Ramón Casaus.

A consecuencia de la diligencia que V.M. ha practicado con el platero $\mathrm{D}^{\mathbf{n}}$. Jph. Luis Rodz. sobre el reconocimiento y entrega del Quaderno de Estampas y de las 16 sueltas que pidió en su escrito por ignorarse quales sean, acompaño a V. M. las adjuntas para que haciendo comparecer al expresado platero haverigue con cautela qué clase de estampas son las suias y que sidndo las mismas le entregue V. M. las que no tengan nota (conforma al $\mathrm{N}^{\bullet}$ dicho) y las demás las devuelva a este Tribl. lo que de lo que de su orden comunico a V. M. a quien Dios $q^{e}$. $m^{*}$. a".

Inqon. de México, 20 de Abril de 1799.

Bernardo Ruiz de Molina.Rública.

Ilmo. Sr.

Quando remití a V.S.I. las 10 estampas, no creí que eran más las que algunos días antes había arrancado del Libro de Rodríguez. El oficio de V.S.I. me hizo dudar si fueron mas y así registré con mayor cuidado mi papelera y he hallado entre los pa-peles estas quatro estampas que ahora remito. Quando vino a mi reconocimiento el Libro ya le faltaban dos; una estampa y la última viñeta; y Rodríguez me dijo que la tenía con su marco. $Y$ así no son más que 14 las arrancadas por orden de V.S.I. y la equivocación está en el Platero, que dos que el había quitado y al menos de una me lo confesó quando le entregué el Libro.

No me parece es necesario preguntarle nada porque ya queda con esto aclarada la duda, ocasionada de mi involuntaria omisión quando remití las 10 estampas y del olvido de Rodz. que pide dos más que él ha de tener.

Colegio de St. Domingo de Porta Coeli a 24 de Abril de 1799.

Ilmo.

$$
\text { Dr. Fr. Ramón Casaus y Torres, Calificador.-Rúbrica. }
$$

\section{Pies de las Estampas}

La Nyphe Hesperie fuyant Esaque qui l'aimoit fut piqué par un serpent et mourut de la blessure.

C. Monnet Inv.

Louis Legrand Scu.

L'Aurore appergoit Cephale dont elle devinent amoureuse et l'enleve.

F. Boucher Inv.

Aug. de St. Aubin Sculp.

Venus appuyée sur son cher Adonis lui conseille de ne chasser que les bêtes a qui la nature n'a point donné des armes.

F. Boucher Inv.

Massard sc. 
Thetis ecoute Protée qui lui predit qu'elle auroit un fils plus puissant que son père.
C. Monnet Inv.
N. Le Mire Sculp.

Les Nymphees decouvrent a Diane la grossesse de Calisto.

Ch. Eisen Inv.

N. Le Mire Sculp.

Jupiter descend avec toute sa Majesté dans le Palais de Sémele.

J. M. Moreau Inv.

D. Née Sculp.

Mars et Venus, dont Apollon decouvre le comerce et en instruit Vulcain.

F. Boucher Inv. N. Le Mire sc.

Leucohoé, charmée de la beauté d'Apollon se laisse vaincre sans resistance.

C. Monnet del. Simonet sc.

Ou fuyez vous belle Aréthuise, s'ecrie alors Alphée, ou fuyez vous? Moreau del. Basan sc.

La Nymphe Salmaces veut embrasser le jeune Hermaphrodite, qu'elle voit dans le Bain.

C. Monnet.

Massard.

Jupiter couvre la Terre de nuages pour jouir d'Io.

C. Monnet.

N. Le Mire.

Jupiter prend la forme de Diane pour rendre sensible la Nymphe Calisto. Ch. Eisen Inv.

J. B. Simonet Sculp.

L'Age d'or et l'age d'argent, ou regner eut l'innocence et la Justice.

C. Eisen Inv. et del. N. Le Mire Sculp.

Polypheme aprés azoir chanté les louanges de Galatée l'apercoit aux pieds du Rocher qui sentretenoit avec Acis.

Dessiné para J. M. Moreau le Jeune Gravé S. C. Miger 1769. 